\title{
Sleep disturbance and cardiovascular risk in adolescents
}

\author{
Indra Narang MB BCh MD, Cedric Manlhiot BSc, Jolie Davies-Shaw BDes MA, Don Gibson NP PHC, \\ Nita Chahal RN (EC) MN NP-Paeds, Karen Stearne BSC, Amanda Fisher, Stafford Dobbin MB, \\ Brian W. McCrindle MD MPH
}

\begin{abstract}
Background: Evidence suggests that inadequate or disturbed sleep is associated with increased cardiovascular risk in adults. There are limited data on sleep quality and associated cardiovascular risk in children.

Methods: We obtained data on adolescents from the 2009/10 cycle of the Healthy Heart Schools' Program, a population-based crosssectional study in the Niagara region of Ontario. Participants underwent measurements of cardiometabolic risk factors, including body mass index (BMI), lipid profile and blood pressure, and they completed questionnaires measuring sleeping habits and nutritional status. We assessed sleep disturbance using the sleep disturbance score derived from the Pittsburgh Sleep Quality Index. We explored associations between sleeping habits and cardiovascular risk factors.
\end{abstract}

Results: Among 4104 adolescents (51\% male), the mean hours of sleep per night ( \pm standard deviation) were $7.9 \pm 1.1$ on weeknights and
$9.4 \pm 1.6$ on weekends. In total, $19 \%$ of participants reported their sleep quality as fairly bad or very bad on weeknights and $10 \%$ reported it as fairly bad or very bad on weekends. In the multivariable regression models, a higher sleep disturbance score was associated with increased odds of being at high cardiovascular risk (highest v. lowest tertile odds ratio [OR] 1.43 [95\% confidence interval $(\mathrm{Cl})$ 1.16-1.77], $p<0.001)$, increased odds of hypertension (highest v. lowest tertile OR 1.44 [95\% Cl 1.02-2.05], $p=0.05$ ) and increased odds of elevated non-high density lipoprotein cholesterol (highest v. lowest tertile OR 1.28 [95\% Cl 1.00-1.64], $p=0.05$ ). The mean duration of sleep was not associated with these outcomes.

Interpretation: In healthy adolescents, sleep disturbance is associated with cardiovascular risk factor abnormalities. Intervention strategies to optimize sleep hygiene early in life may be important for the prevention of cardiovascular disease.
$\mathrm{T}$ here is emerging evidence in experimental and epidemiologic studies that sleep parameters, specifically sleep duration and quality, are associated with cardiovascular outcomes, including hypertension, ${ }^{1}$ as well as diabetes, ${ }^{2}$ hypercholesterolemia ${ }^{3}$ and obesity. ${ }^{4} \mathrm{~A}$ recent meta-analysis involving 400000 adults concluded that short sleep duration was associated with a greater risk of developing or dying from coronary heart disease. ${ }^{5} \mathrm{On}$ average, adolescents sleep less than 8 hours per night, ${ }^{6}$ less than the recommended 9 hours, ${ }^{7}$ and about $20 \%$ of adolescents have significant sleep problems. ${ }^{6}$ Despite this knowledge, there is a paucity of epidemiologic research on the cardiovascular consequences of short sleep duration and impaired sleep quality in adolescents.

In this study, we investigated the association between sleep disturbance and duration and measures of cardiovascular disease risk, including cholesterol, hypertension, body mass index (BMI) and dietary factors in adolescents.

\section{Methods}

This study was conducted through the Healthy Heart Schools' Program, which was designed to screen and identify adolescents at risk for coronary vascular disease. This program targets adolescents in the Niagara region of Ontario during their mandatory physical education class. The current data were collected during the 2009/10 school year.

\section{Data collection}

Participants completed the Pittsburg Sleep Quality Index questionnaire, ${ }^{8}$ which is a validated tool for use in adults and has been administered in clinical adolescent populations. ${ }^{9,10}$ The questionnaire uses a 19-item scale designed to measure self-reported sleep duration, overall perception of quality of sleep, sleep disturbances, daytime sleepiness, history of snoring and the use of any sleep medication over a 1-month period. The questions were designed to reflect both weeknight and weekend
Competing interests: None declared.

This article has been peer reviewed.

Correspondence to: Brian W. McCrindle, brian.mccrindle@sickkids.ca

CMAJ 2012. DOI:10.1503 /cmaj.111589 
sleep. We developed an overall sleep disturbance score using the answers to the 15 questions listed in Table 1. The answer "Not during the past month" was given a score of 0 , "less than once per week" was scored as 1, "once or twice per week" was scored as 2 and " 3 or more times per week" was scored as 3, according to the validated scoring system. ${ }^{8}$ The maximum score was 45 points, with higher scores reflecting worse sleep quality. Because no clinically significant score is defined for sleep disturbance, we divided the population into tertiles to avoid any misclassification and to evaluate dose response. The lifestyle assessment section of the questionnaire ascertained the amount of physical activity and screen time (television, video games and computer time) per week. Participants completed an adapted version of the Child and Adolescent Trial for Cardiovascular Health nutrition questionnaire. ${ }^{11}$

The study protocol was reviewed and approved by the research ethics board of the District School Board of Niagara and the Niagara Catholic District School Board. All enrolled participants provided informed assent; parental consent was also obtained.

\section{Measurements}

All physical measurements were performed by trained Heart Niagara staff during class time. All participants underwent height (stadiometer) and weight (calibrated scales) measurements in a standardized manner. We then converted these values to age- and sex-based percentiles and to $z$ scores. ${ }^{12}$ Overweight was defined as BMI between the 85th and 95th percentiles, and obesity was defined as BMI above the 95th percentile. ${ }^{13}$ Waist circumference measurement was standardized and concordant with methods used in the National Health and Nutrition Examination Survey, from which normal values for adolescents were used to determine age- and sexspecific percentile categories. ${ }^{14}$ Capillary blood samples obtained by finger stick were used to determine nonfasting total and high density lipoprotein (HDL) cholesterol levels (Cholestech LDX System, Inverness Medical Innovations). We classified total cholesterol levels between 4.4 and $5.1 \mathrm{mmol} / \mathrm{L}$ as borderline high, and levels $5.2 \mathrm{mmol} / \mathrm{L}$ or higher were classified as high. ${ }^{15}$

Blood pressure was evaluated in a standardized manner (sitting) using a Bp TRU blood pressure monitor (Coquitlman) using an appropriatesized cuff on the participant's right upper arm. ${ }^{16}$ Participants with an initial blood pressure measurement above the normal range $(\geq 135 / 85$ $\mathrm{mm} \mathrm{Hg}$ ) underwent repeat testing. If the second measurement was also above the normal range, 6 automated readings were taken at 1-minute intervals, and the average was calculated. ${ }^{16}$ We converted the systolic and diastolic readings to age-, sex- and height-indexed percentiles. ${ }^{16}$ We used the maximum percentiles of the blood pressure readings to classify participants as prehypertensive ( $>90$ th to $<95$ th percentile) or stage I hypertensive ( $\geq$ 99th percentile) ${ }^{16}$ We considered patients with the following measurements to be

Table 1: Frequency of sleep disturbances among 3372 adolescents

\begin{tabular}{|llrrr|r|}
\hline & \multicolumn{5}{c|}{ No. (\%) } \\
\cline { 2 - 6 } Variable & $\begin{array}{c}\text { Not during the } \\
\text { past month }\end{array}$ & $\begin{array}{c}\text { Less than once } \\
\text { per week }\end{array}$ & $\begin{array}{c}\text { Once or twice } \\
\text { per week }\end{array}$ & $\begin{array}{c}\text { Three or more } \\
\text { times per week }\end{array}$ \\
\hline Woke up during night/early morning & $1178(35.9)$ & $939(28.6)$ & $678(20.7)$ & $485(14.8)$ \\
\hline Could not fall asleep within 30 min & $1403(42.8)$ & $782(23.8)$ & $552(16.8)$ & $543(16.6)$ \\
\hline Felt too hot & $1739(53.3)$ & $809(24.8)$ & $483(14.8)$ & $229(7.0)$ \\
\hline Felt too cold & $1842(56.5)$ & $773(23.7)$ & $432(13.0)$ & $225(6.9)$ \\
\hline Got up to use the bathroom & $1865(56.7)$ & $821(25.0)$ & $409(12.4)$ & $192(5.8)$ \\
\hline Had bad dreams & $2245(68.8)$ & $617(18.9)$ & $263(8.1)$ & $139(4.3)$ \\
\hline Legs twitched or jerked & $2234(75.0)$ & $364(12.2)$ & $203(6.8)$ & $176(5.9)$ \\
\hline Had pain & $2485(76.5)$ & $477(14.7)$ & $187(5.8)$ & $98(3.0)$ \\
\hline Coughed/snored loudly (self-reported) & $2662(81.8)$ & $339(10.4)$ & $139(4.3)$ & $113(3.5)$ \\
\hline Snored loudly (reported by parents) & $2550(84.6)$ & $232(7.7)$ & $105(3.5)$ & $126(4.2)$ \\
\hline Could not breathe comfortably & $2781(85.4)$ & $269(8.3)$ & $137(4.2)$ & $69(2.1)$ \\
\hline Restlessness while asleep & $2395(89.2)$ & 116 & $(4.3)$ & $82(3.1)$ & 93 \\
\hline Disoriented or confused & $2658(89.6)$ & $194(6.5)$ & $71(2.4)$ & $42(1.4)$ \\
\hline Disturbed sleep for other reasons & $2193(90.5)$ & $57(2.4)$ & $70(2.9)$ & $102(4.2)$ \\
\hline Long pause between breath & $2758(92.7)$ & $128(4.3)$ & $48(1.6)$ & $42(1.4)$ \\
\hline
\end{tabular}


at high cardiovascular risk: non-HDL cholesterol $>3.10 \mathrm{mmol} / \mathrm{L}$; blood pressure $>90$ th percentile; or BMI > 85th percentile.

We defined a history of premature cardiovascular disease in first-degree relatives as a relative with angina, heart attack, bypass surgery or stroke before the age of 65 years for female relatives and before the age of 55 years for male relatives.

\section{Statistical analysis}

We report data as means ( \pm standard deviations [SD]), median (interquartile range [IQR]) and frequencies, as appropriate. We decided to use tertiles for the sleep disturbance scores and quar- tiles for sleep duration to create groups of roughly equal sizes while accommodating the variable distribution.

We assessed the association between sleep disturbance score tertiles, sleep duration quartiles and cardiometabolic risk factors in univariable linear regression models. We used a similar approach to investigate the association between sleep outcomes, lifestyle and sleep disturbance scores. We created additional multivariable ordinal logistic regression models to identify the independent effect of sleep duration and quality on cardiovascular risk factors beyond the other cardiovascular risk factors and lifestyle. We created dual sets of

Table 2: Association between sleep parameters and sleep disturbance scores*

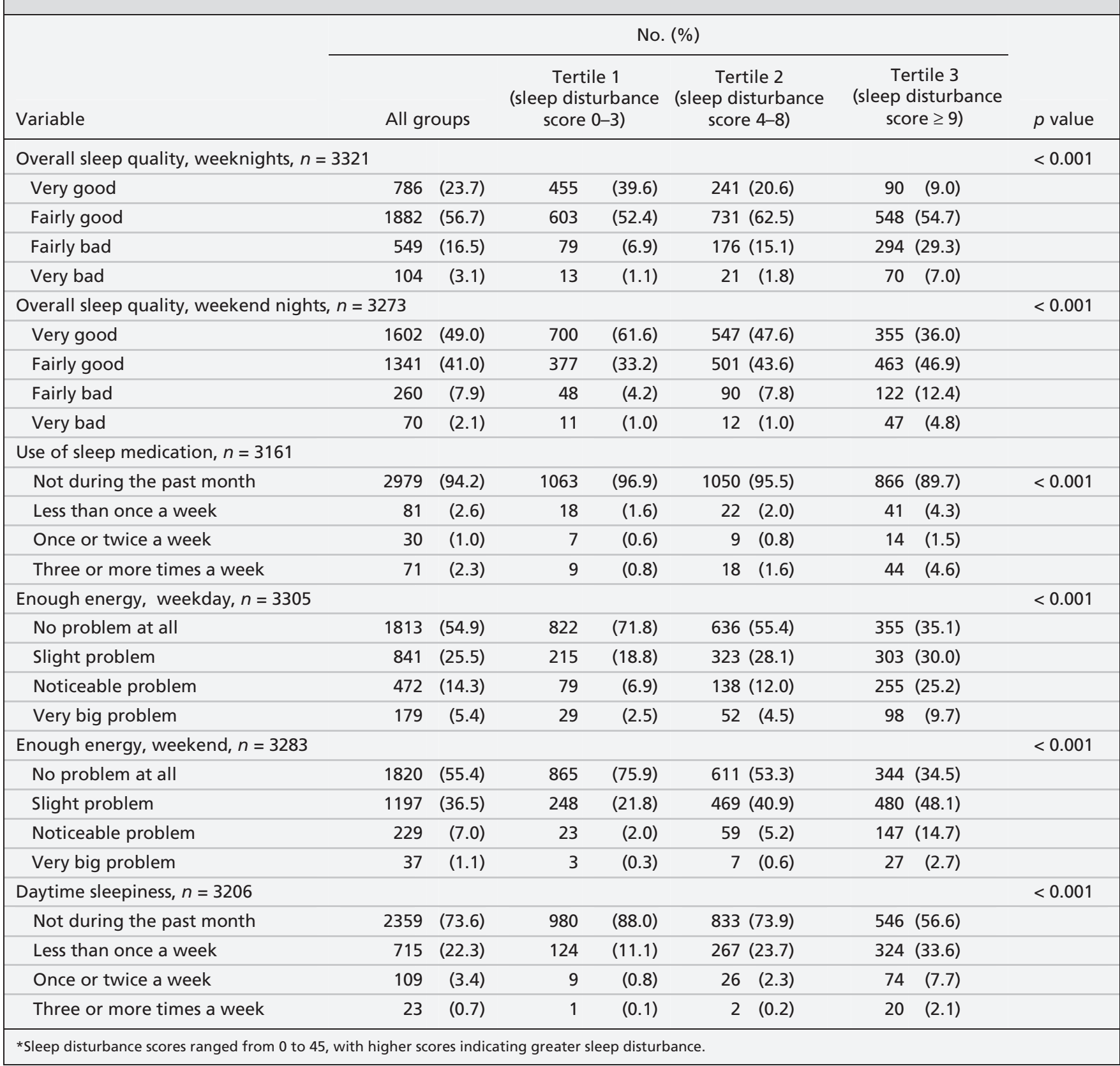


regression models: initially, sleep disturbance scores and sleep duration were modelled as continuous variables; further regression models used sleep duration and sleep disturbance index as quartiles and tertiles, respectively. We selected factors based on clinical relevance (regardless of $p$ value) and previous association with cardiometabolic outcomes in this population. ${ }^{17}$ We adjusted for adiposity using waist circumference percentiles, because we have previously shown that waist circumference has a greater association with cardiometabolic risk than BMI $z$ score. ${ }^{18}$ We did not use stepwise modelling in this study. All regression models used a maximum likelihood algorithm to determine parameter estimates.

\section{Results}

In total, 4104 adolescents (51\% male) were enrolled in this study out of 4884 (84\%) eligible students. Students were not included if they attended physical education class in the summer, were absent or did not provide consent. Complete sleep questionnaires were available for 3372 (82\%) students. The characteristics of this population were similar to those included in previously reported population-based studies..$^{1920}$

The mean hours of sleep per night $( \pm$ SD) were $7.9 \pm 1.1 \mathrm{~h}$ on weekdays and $9.4 \pm 1.6 \mathrm{~h}$ on week- ends $(p<0.001)$. The median sleep disturbance score was 5 (IQR 2-10; tertile $1=0-3$; tertile $2=$ 4-8; tertile 3 9). The frequency of specific types of sleep disturbances are presented in Table 1. A higher sleep disturbance score was associated with fewer hours of sleep during weeknights (highest tertile $7.6 \pm 1.3 \mathrm{~h}$ v. lowest tertile $8.2 \pm 1.0 \mathrm{~h} ; p<$ 0.001 ) and weekend nights (highest tertile $9.2 \pm$ $1.8 \mathrm{~h}$ v. lowest tertile $9.5 \pm 1.6 \mathrm{~h} ; p<0.001)$.

In total, $19.6 \%$ of students reported that their sleep quality during the week was fairly bad or bad; $10.0 \%$ of students rated their weekend sleep quality as fairly bad or bad $(p<0.001)$ (Table 2$)$. Of the participants, $5.9 \%$ reported using sleep medications. There was a statistically significant association between sleep disturbance score and overall self-reported sleep quality on weeknights $(r=0.39$, $p<0.001)$ and weekend nights $(r=0.27, p<$ 0.001 ). The use of sleep medication was associated with a mean $( \pm$ SD) decrease of $0.32 \pm 0.09 \mathrm{~h}$ of sleep on week nights $(p<0.001)$, a decrease of $0.45 \pm 0.13 \mathrm{~h}$ on weekends $(p<0.001)$ and an increase of $4.0 \pm 0.4$ points in the sleep disturbance score $(p<0.001)$. Daytime sleepiness was associated with lower sleep duration and a higher sleep disturbance scores (Table 2).

In total, $18 \%$ of participants consumed more than 1 cup of caffeinated beverages per day, $72 \%$ consumed 1 cup per day and $11 \%$ did not con-

Table 3: Association between nutrition, physical activity and sleep disturbance scores*

\begin{tabular}{|c|c|c|c|c|c|c|c|}
\hline Variable & No. $(\%)$ & $\begin{array}{c}\text { Sleep disturbance } \\
\text { score, } \\
\text { mean } \pm \text { SD }\end{array}$ & No. $(\%)$ & $\begin{array}{c}\text { Sleep disturbance } \\
\text { score, } \\
\text { mean } \pm \text { SD }\end{array}$ & No. $(\%)$ & $\begin{array}{l}\text { eep disturbance } \\
\text { score, } \\
\text { mean } \pm \text { SD }\end{array}$ & $p$ value \\
\hline Nutrition & \multicolumn{2}{|c|}{ No serving } & \multicolumn{2}{|c|}{1 serving/d } & \multicolumn{2}{|c|}{$>1$ serving/d } & \\
\hline $\begin{array}{l}\text { Battered or fried } \\
\text { chicken, steak or fish }\end{array}$ & $2579(78.1)$ & $6.6 \pm 5.6$ & $642(19.5)$ & $7.1 \pm 5.9$ & $80 \quad(2.4)$ & $8.3 \pm 6.9$ & 0.001 \\
\hline French fries or chips & $1857(56.4)$ & $6.4 \pm 5.7$ & $1146(34.8)$ & $7.1 \pm 5.7$ & $290 \quad(8.8)$ & $7.7 \pm 6.0$ & $<0.001$ \\
\hline Soft drinks & $2013(61.0)$ & $6.5 \pm 5.6$ & $916(27.8)$ & $6.9 \pm 5.8$ & $370(11.2)$ & $7.2 \pm 5.6$ & 0.01 \\
\hline $\begin{array}{l}\text { Sweet rolls, pies, } \\
\text { doughnuts or cookies }\end{array}$ & $1781(54.1)$ & $6.4 \pm 5.5$ & $1155(35.1)$ & $7.0 \pm 5.7$ & 359 (10.9) & $7.3 \pm 6.2$ & $<0.001$ \\
\hline Snacks & $236 \quad(7.2)$ & $6.1 \pm 5.9$ & $942(28.8)$ & $6.5 \pm 5.6$ & $2090(64.0)$ & $6.9 \pm 5.7$ & $<0.001$ \\
\hline $\begin{array}{l}\text { Caffeinated beverages } \\
\text { (combined) }\end{array}$ & $347(10.5)$ & $4.8 \pm 4.8$ & 2357 (71.5) & $6.6 \pm 5.6$ & $592(18.0)$ & $8.1 \pm 6.3$ & $<0.001$ \\
\hline $\begin{array}{l}\text { Coffee, caffeinated } \\
\text { tea or espresso }\end{array}$ & $1881(56.4)$ & $5.9 \pm 5.2$ & $1349(40.5)$ & $7.6 \pm 6.1$ & $179 \quad(5.4)$ & $9.2 \pm 6.6$ & $<0.001$ \\
\hline Caffeinated soft drinks & $761(22.9)$ & $5.9 \pm 5.6$ & $2380(71.7)$ & $6.9 \pm 5.6$ & $179 \quad(5.4)$ & $7.7 \pm 6.4$ & $<0.001$ \\
\hline Hot chocolate & $2081(62.5)$ & $6.4 \pm 5.6$ & $1232(37.0)$ & $7.3 \pm 15.8$ & $17 \quad(0.5)$ & $10.3 \pm 7.2$ & $<0.001$ \\
\hline Physical activity & \multicolumn{2}{|c|}{$0-2 \mathrm{~d} / \mathrm{wk}$} & \multicolumn{2}{|c|}{ 3-4 d/wk } & \multicolumn{2}{|c|}{ 5-7 d/wk } & \\
\hline $\begin{array}{l}\text { Moderate to vigorous } \\
\text { physical activity }\end{array}$ & $660(19.9)$ & $7.4 \pm 5.9$ & 782 (23.6) & $7.2 \pm 5.6$ & $1871(56.5)$ & $6.3 \pm 5.6$ & $<0.001$ \\
\hline & \multicolumn{2}{|c|}{$0-5 \mathrm{~h} / \mathrm{d}$} & \multicolumn{2}{|c|}{$6-10 \mathrm{~h} / \mathrm{d}$} & \multicolumn{2}{|c|}{$>10 \mathrm{~h} / \mathrm{d}$} & \\
\hline Screen time & $1797(56.1)$ & $6.2 \pm 5.4$ & 1187 (37.0) & $7.3 \pm 5.7$ & $222(6.9)$ & $7.9 \pm 6.3$ & $<0.001$ \\
\hline
\end{tabular}


Table 4: Association between cardiometabolic risk factors and sleep disturbance score*

\begin{tabular}{|c|c|c|c|c|c|c|}
\hline \multirow[b]{2}{*}{ Variable } & \multirow[b]{2}{*}{$N$} & \multirow[b]{2}{*}{ All groups } & \multicolumn{3}{|c|}{ Mean \pm SD or no $(\%)$} & \multirow[b]{2}{*}{$p$ value } \\
\hline & & & $\begin{array}{c}\text { Tertile } 1 \\
\text { (sleep disturbance } \\
\text { score } 0-3 \text { ) }\end{array}$ & $\begin{array}{l}\text { Tertile } 2 \\
\text { (sleep disturbance } \\
\text { score } 4-8 \text { ) }\end{array}$ & $\begin{array}{c}\text { Tertile } 3 \\
\text { (sleep disturbance } \\
\text { score } \leq 9 \text { ) }\end{array}$ & \\
\hline No. (\%) of participants & & & $1171(34.7)$ & $1176(34.9)$ & $1025(30.4)$ & \\
\hline Age at assessment, yr & 3372 & $14.6 \pm 0.5$ & $14.6 \pm 0.5$ & $14.6 \pm 0.5$ & $14.6 \pm 0.5$ & 0.2 \\
\hline Male & 3372 & $1650(48.9)$ & $694(59.3)$ & $586(49.8)$ & $370(36.1)$ & $<0.001$ \\
\hline \multicolumn{7}{|l|}{ Hours of sleep } \\
\hline Weeknights & 3235 & $7.9 \pm 1.1$ & $8.2 \pm 1.0$ & $8.0 \pm 1.1$ & $7.6 \pm 1.3$ & $<0.001$ \\
\hline Weekend nights & 3176 & $9.4 \pm 1.6$ & $9.5 \pm 1.6$ & $9.4 \pm 1.6$ & $9.2 \pm 1.8$ & $<0.001$ \\
\hline Average & 3372 & $8.4 \pm 1.0$ & $8.6 \pm 0.9$ & $8.4 \pm 1.0$ & $8.0 \pm 1.1$ & $<0.001$ \\
\hline Quartile 1: $\leq 7.75 \mathrm{~h}$ & & $966(28.7)$ & $231(19.7)$ & $324(27.6)$ & $411(40.1)$ & $<0.001$ \\
\hline Quartile 2: $>7.75$ to $\leq 8.40 \mathrm{~h}$ & & $784(23.3)$ & $275(23.5)$ & $268(22.8)$ & $241(23.5)$ & \\
\hline Quartile 3: $>8.40$ to $\leq 9.00 \mathrm{~h}$ & & $897(26.6)$ & $361(30.8)$ & $320(27.2)$ & $216(21.1)$ & \\
\hline Quartile 4: > $9.00 \mathrm{~h}$ & & $725(21.5)$ & $304(26.0)$ & $264(22.5)$ & $157(15.3)$ & \\
\hline $\begin{array}{l}\text { History of premature } \\
\text { cardiovascular disease in } \\
\text { first-degree relativet }\end{array}$ & 3227 & $1057(32.8)$ & $324(28.7)$ & $367(32.4)$ & $366(37.8)$ & $<0.001$ \\
\hline \multicolumn{7}{|l|}{ Lipid profile } \\
\hline Total cholesterol, $\mathrm{mmol} / \mathrm{L}$ & 2955 & $3.85 \pm 0.74$ & $3.81 \pm 0.72$ & $3.83 \pm 0.73$ & $3.92 \pm 0.78$ & 0.003 \\
\hline$>5.2 \mathrm{mmol} / \mathrm{L}$ (high) & & $137 \quad(4.6)$ & $43(4.2)$ & 45 (4.3) & $49 \quad(5.6)$ & 0.03 \\
\hline$>4.4-5.2 \mathrm{mmol} / \mathrm{L}$ (borderline) & & $494(16.7)$ & $157(15.3)$ & $164(15.6)$ & $173(19.6)$ & \\
\hline HDL cholesterol & 2953 & $1.23 \pm 0.33$ & $1.21 \pm 0.33$ & $1.23 \pm 0.33$ & $1.23 \pm 0.34$ & 0.3 \\
\hline Non-HDL cholesterol & 2955 & $2.63 \pm 0.72$ & $2.60 \pm 0.70$ & $2.60 \pm 0.72$ & $2.70 \pm 0.75$ & 0.003 \\
\hline > 3.75 mmol/L (high) & & $215(7.3)$ & $66(6.4)$ & $74(7.1)$ & 75 (8.5) & 0.003 \\
\hline$>3.10$ to $3.75 \mathrm{mmol} / \mathrm{L}$ (borderline) & & $446(15.1)$ & $147(14.3)$ & $137(13.1)$ & $162(18.4)$ & \\
\hline \multicolumn{7}{|l|}{ Adiposity } \\
\hline BMI z score $\neq$ (5th, 95th percentile) & 3277 & $0.5(-0.2,1.4)$ & $0.4(-0.3,1.3)$ & $0.5(-0.3,1.3)$ & $0.7(-0.1,1.5)$ & $<0.001$ \\
\hline Overweight (> 85-95\%) & & $480(14.7)$ & $150(13.2)$ & $172(15.0)$ & $158(15.9)$ & 0.005 \\
\hline Obese $(>95 \%)$ & & $612(18.7)$ & $206(18.1)$ & $189(16.5)$ & $217(21.8)$ & \\
\hline Waist circumference percentile & 3270 & & & & & 0.02 \\
\hline$<10$ th & & $307(9.4)$ & $119(10.5)$ & $103(9.0)$ & $85(8.6)$ & \\
\hline 10th-24th & & $399(12.2)$ & $145(12.8)$ & $147(12.9)$ & $107(10.8)$ & \\
\hline 25th-49th & & $814(24.9)$ & $285(25.1)$ & $299(26.1)$ & $230(23.2)$ & \\
\hline 50th-74th & & $900(27.5)$ & $311(27.4)$ & $315(27.5)$ & $274(30.5)$ & \\
\hline 75th-90th & & $548(16.7)$ & $176(15.5)$ & $196(17.1)$ & $176(17.8)$ & \\
\hline$>90$ th & & $302 \quad(9.2)$ & 99 (8.7) & $84 \quad(7.3)$ & $119(12.0)$ & \\
\hline \multicolumn{7}{|l|}{ Blood pressure } \\
\hline $\begin{array}{l}\text { Systolic blood pressure } z \text { score } \neq \\
\text { (5th, 95th percentile) }\end{array}$ & 3255 & $-0.6(-1.3,0.1)$ & $-0.6(-1.3,0.0)$ & $-0.7(-1.3,0.0)$ & $-0.6(-1.2,0.1)$ & 0.007 \\
\hline $\begin{array}{l}\text { Diastolic blood pressure } z \text { score } \neq \\
\text { (5th, 95th percentile) }\end{array}$ & 3252 & $0.1(-0.4,0.6)$ & $0.1(-0.4,0.6)$ & $0.0(-0.5,0.5)$ & $0.1(-0.4,0.6)$ & 0.09 \\
\hline Pre-hypertension (90th-95th) & 3252 & $163(5.0)$ & $47 \quad(4.2)$ & $48 \quad(4.2)$ & 68 (6.9) & 0.05 \\
\hline Stage 1 or 2 (> 95th) & & 114 (3.5) & 37 (3.3) & $40 \quad(3.5)$ & 37 (3.7) & \\
\hline Cardiovascular riskף & 2919 & $1231(42.2)$ & $398(39.3)$ & $415(40.0)$ & $418(48.1)$ & $<0.001$ \\
\hline \multicolumn{7}{|c|}{$\begin{array}{l}\text { Note: } \mathrm{BMI}=\text { body mass index, } \mathrm{HDL}=\text { high-density lipoprotein, } \mathrm{SD}=\text { standard deviation. } \\
\text { *Sleep disturbance scores ranged from } 0 \text { to } 45, \text { with higher scores indicating greater sleep disturbance. } \\
\text { †Defined as angina, heart attack, heart or bypass surgery, or stroke before age } 65 \text { in women or before age } 55 \text { in men. } \\
\text { ¥The } z \text { score represents how many standard deviations a measurement is above or below the mean value for that measurement in a normal age- and gender- } \\
\text { matched population. } \\
\text { ПDefined as non-HDL cholesterol }>3.10 \mathrm{mmol} / \mathrm{L}, \mathrm{BMI}>85 \text { th percentile or blood pressure }>90 \text { th percentile. }\end{array}$} \\
\hline
\end{tabular}




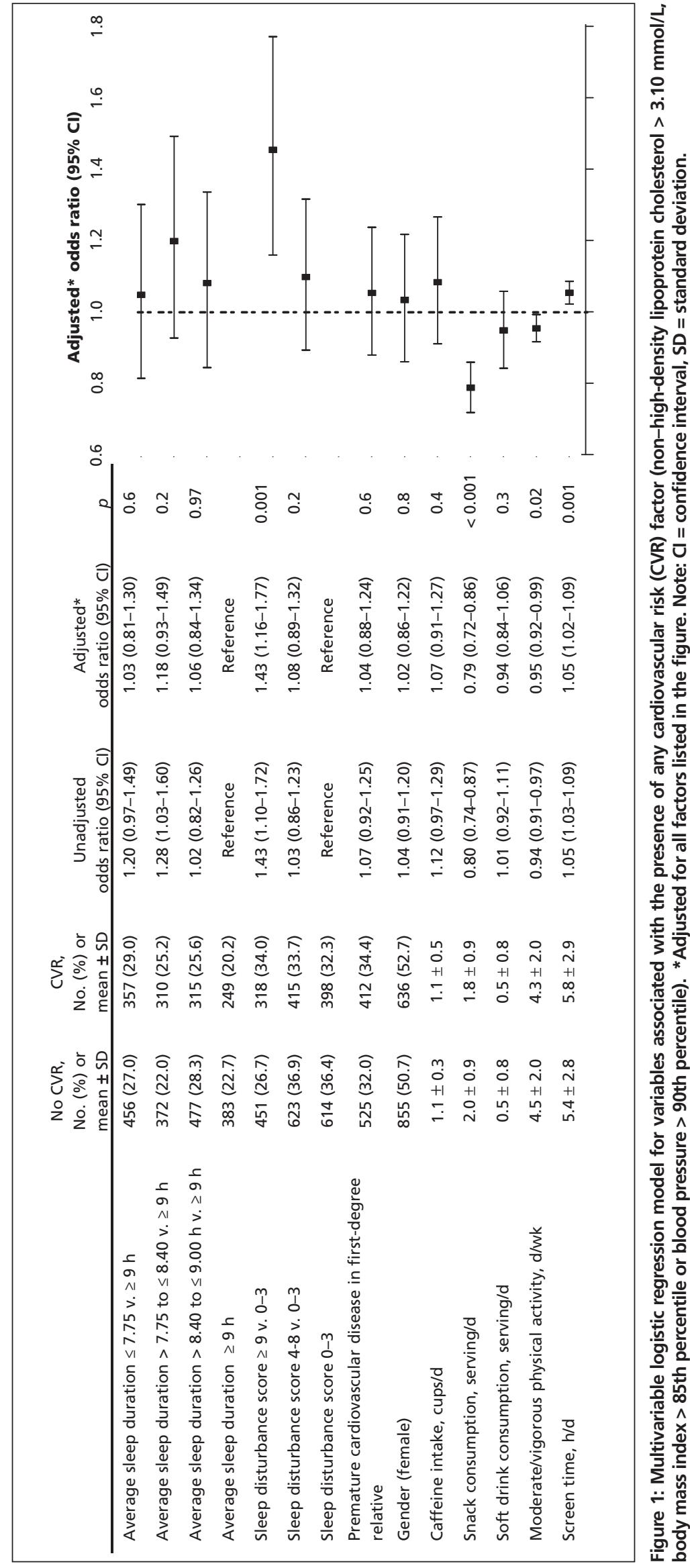

sume caffeine at all. A higher sleep disturbance score was associated with higher consumption of fried food, soft drinks, sweets, snacks, caffeinated beverages, reduced physical activity and increased screen time (Table 3). Shorter sleep duration was associated with increased consumption of soft drinks $(p<0.001)$ and increased intake of caffeinated beverages $(p<0.001)$ but not with other high fat, high sugar foods. Overweight and obese participants had a higher prevalence of daily consumption of caffeinated beverages than the leaner participants (94\% and $88 \%$, respectively; $p=$ 0.04). Consumption of caffeinated beverages was significantly associated with increased intake of fried chicken, chips and soda. Shorter sleep duration was also associated with decreased physical activity (shortest quartile, mean $\pm \mathrm{SD}, 4.1 \pm$ $2.1 \mathrm{~d} / \mathrm{wk} \mathrm{v}$. longest quartile $4.5 \pm 2.0 \mathrm{~d} / \mathrm{wk} ; p<$ 0.001 ) and increased screen time (shortest quartile, mean $\pm \mathrm{SD}, 6.1 \pm 3.2 \mathrm{~h}$ per day v. longest quartile $5.2 \pm 2.9$ h per day; $p<0.001$ ).

A higher sleep disturbance score was associated with higher total cholesterol, higher nonHDL cholesterol, higher BMI $z$ scores, higher waist percentile category, higher systolic blood pressure $z$ scores and increased odds of hypertension (Table 4). Shorter average sleep duration was associated with higher BMI $z$ score (shortest quartile $0.76 \mathrm{v}$. longest quartile $0.41, p<0.001$ ) and a higher proportion with waist circumference above the 75th percentile (shortest quartile $30.0 \%$ v. longest quartile $22.1 \%, p=0.002$ ). There was no association between average sleep duration and lipid profile or blood pressure $z$ scores.

In the multivariable regression models adjusted for lifestyle factors, we found that sex and family history of premature cardiovascular disease in first degree relatives and sleep disturbance were associated with cardiovascular risk (highest v. lowest tertile OR 1.43 [95\% CI 1.16-1.77], $p<0.001$ ), but average sleep duration was not associated (shortest v. longest quartile OR 1.03 [95\% CI 0.81-1.30], $p=0.6$ ) (Figure 1). The results were similar when sleep duration and sleep disturbance scores were modelled as continuous variables (Appendix 1, available at www.cmaj.ca/lookup /suppl/doi:10.1503/cmaj.111589/-/DC1).

In the multivariable regression models adjusted for lifestyle factors (nutrition and physical activity), sex, family history of premature cardiovascular disease in first degree relatives and adiposity, the sleep disturbance score was associated with increased odds of hypertension (highest v. lowest tertile OR 1.44 [95\% CI 1.02-2.05], $p=0.05$ ) (Appendix 2, available at www.cmaj.ca/lookup/suppl/doi :10.1503/cmaj.111589/-/DC1) and increased odds of elevated non-HDL cholesterol (highest v. lowest tertile OR 1.28 [95\% CI 1.00-1.64], $p=0.05$ ) 
(Appendix 3, available at www.cmaj.ca/lookup /suppl/doi:10.1503/cmaj.111589/-/DC1). Average sleep duration was not associated with hypertension (shortest v. longest quartile OR $0.62[95 \% \mathrm{CI}$ 0.42-1.09], $p=0.1$ ) (Appendix 2) or non-HDL cholesterol (shortest v. longest quartile, OR 0.92 [95\% CI 0.70-1.22], $p=0.2$ ) (Appendix 3). The models that evaluated hypertension and nonHDL cholesterol yielded similar results for sleep duration and sleep disturbance scores, whether the sleep variables were modelled as ordinal or continuous (Appendices 4 and 5, available at www.cmaj.ca/lookup/suppl/doi:10.1503 /cmaj.111589/-/DC1).

\section{Interpretation}

We found an association between sleep disturbance and cardiovascular risk in adolescents, as determined by high cholesterol levels, increased BMI and hypertension. These findings are important, given that sleep disturbance is highly prevalent in adolescence ${ }^{6}$ and that cardiovascular disease risk factors track from childhood into adulthood. ${ }^{19}$

In a study involving over 14000 adolescents, short sleep duration documented 5 years earlier was a significant risk factor for high cholesterol in adulthood..$^{20}$ However, that study was limited by reliance on self-reporting of apparent high cholesterol levels..$^{20}$ Recently, short sleep duration $(<6.5 \mathrm{~h})$ in Chinese adolescents was reported to be associated with measured high total cholesterol, ${ }^{21}$ although sleep disturbance was not evaluated in that cohort. In a cross-sectional analysis of 238 adolescents, the odds of prehypertension were increased 3.5-fold for low sleep efficiency and 2.5 -fold for short sleep duration (defined as $<6.5 \mathrm{~h}$ ); however, cholesterol measurements were not obtained..$^{22}$ Recent small community-based studies have also observed trends between short sleep duration, metabolic dysfunction and adiposity in children less than 10 years of age. ${ }^{23,24}$

Mechanisms mediating the relation between inadequate or disturbed sleep, high cholesterol and weight gain include changes in the appetiteregulating hormones ghrelin and leptin, ${ }^{25}$ preference for fatty foods ${ }^{26}$ and circadian alterations in lipid metabolism. ${ }^{26}$ In one study, the odds of obesity increased 5-fold for every hour reduction in sleep duration. ${ }^{27}$ Similarly, Senegalese girls aged 13-14 years had a reduction in sleep of 6.85 minutes for every 1.0 increase in BMI. ${ }^{28}$

However, additional confounding factors may predispose people to adiposity and cardiovascular risk. For example, caffeine consumption (especially high-caffeine energy drinks), preference for fatty foods and reduced physical activity may simply reflect the current "usual" lifestyle of adolescents, which includes short and disturbed sleep. Nonetheless, the relation is likely bidirectional with disturbed sleep leading to daytime sleepiness, decreased physical activity and increased caffeine consumption.

\section{Strengths and limitations}

The strengths of this study were that cholesterol levels were obtained simultaneously with physical measurements and questionnaires assessing sleep and nutrition in over 4000 adolescents. The inclusion of a school-based population strengthens our findings because it minimizes referral bias. Further, our reported incidence of obesity, high cholesterol levels, sleep disturbance and use of sleep medication were similar to other previously reported data. ${ }^{29-31}$

Our study had several limitations. We did not exclude participants with obstructive sleep apnea, which is associated with disrupted sleep, short sleep duration and cardiovascular risk. ${ }^{32}$ In adolescence, the most common cause of obstructive sleep apnea is obesity, and sleep apnea is prevalent in about one-fifth of all obese adolescents. ${ }^{33}$ Because the incidence of obesity in our population was $18 \%$ and less than $8 \%$ of our study group reported that they snore, obstructive sleep apnea is considered an unlikely mediator of major sleep disturbances in this cohort.

This study was conducted within the time and material constraints of the school curriculum. As such, blood pressure, height, weight and waist circumference were measured once only, possibly reducing the reliability of these results. Certainly, more accurate measurements of blood pressure should be verified by 24-hour ambulatory monitoring. Although fasting cholesterol measurements are preferable, non-fasting cholesterol values have been linked to an increased risk of cardiovascular disease in previous population-based studies. ${ }^{34}$ Moreover, recent data suggest that fasting and non-fasting cholesterol levels are comparable. ${ }^{35}$ The sleep questionnaire was not specifically validated for adolescents, and the duration of sleep and sleep disturbance were self-reported on one occasion only without objective assessments. However, it is not usually feasible to obtain objective sleep measurements in large prospective population-based studies. Similarly, eating behaviours were not quantified in a more objective manner. Further, the intake of popular high-caffeine energy drinks was not specifically identified.

Finally, the reported associations do not provide proof of causality, only associations. Some of these associations have limited magnitude; however, previous studies have shown that cardiovascular risk factors and associated lifestyle developed in childhood persist and amplify in adulthood..$^{36-38}$ Thus, it 
is important to interpret our findings with consideration of the biological plausibility of the observations and experimental data showing that sleep disruption may modify cardiovascular risk.

\section{Conclusion}

Poor sleep hygiene among adolescents appears to be associated with increased cardiovascular risk. Future research is needed to dissect the relative influences of sleep curtailment from sleep disruption on different health outcomes. Interventional studies will be necessary to explore the efficacy of optimizing sleep quality, sleep duration and nutrition during adolescence on cardiovascular risk.

\section{References}

1. Cappuccio FP, Stranges S, Kandala NB, et al. Gender-specific associations of short sleep duration with prevalent and incident hypertension: The Whitehall II Study. Hypertension 2007;50: 693-700.

2. Cappuccio FP, D'Elia L, Strazzullo P, et al. Quantity and quality of sleep and incidence of type 2 diabetes: a systematic review and meta-analysis. Diabetes Care 2010;33:414-20.

3. Kaneita Y, Uchiyama M, Yoshiike N, et al. Associations of usual sleep duration with serum lipid and lipoprotein levels. Sleep 2008;31:645-52.

4. Cappuccio FP, Taggart FM, Kandala NB, et al. Meta-analysis of short sleep duration and obesity in children and adults. Sleep 2008;31:619-26.

5. Cappuccio FP, Cooper D, D'Elia L, et al. Sleep duration predicts cardiovascular outcomes: A systematic review and meta-analysis of prospective studies. Eur Heart J 2011;32:1484-92.

6. Gradisar M, Gardner G, Dohnt H. Recent worldwide sleep patterns and problems during adolescence: a review and metaanalysis of age, region, and sleep. Sleep Med 2011;12:110-8.

7. Evolution of sleep and daytime sleepiness in adolescents. In: Guilleminault C, Lugaresi E, editors. Sleep/wake disorders: natural history, epidemiology, and long-term evolution New York (NY): Raven Press; 1983. p. 201-16.

8. Buysse DJ, Reynolds CF III, Monk TH, et al. The Pittsburgh Sleep Quality Index: a new instrument for psychiatric practice and research. Psychiatry Res 1989;28:193-213.

9. Lund HG, Reider BD, Whiting AB, et al. Sleep patterns and predictors of disturbed sleep in a large population of college students. J Adolesc Health 2010;46:124-32.

10. Kaneita Y, Yokoyama E, Harano S, et al. Associations between sleep disturbance and mental health status: a longitudinal study of Japanese junior high school students. Sleep Med 2009;10:780-6.

11. Perry CL, Sellers DE, Johnson C, et al. The Child and Adolescent Trial for Cardiovascular Health $(\mathrm{CATCH})$ : intervention, implementation, and feasibility for elementary schools in the united states. Health Educ Behav 1997;24:716-35.

12. de Onis M, Onyango A, Borghi E, et al. J S. Development of a WHO growth reference for school-aged children and adolescents. Bull World Health Organ 2007;85:660-7.

13. Kuczmarski RJ, Ogden CL, Grummer-Strawn LM, et al. CDC growth charts: United States. Adv Data 2000;8:1-27.

14. Overweight and obesity: NHANES surveys [1976-1980 and 2003-2006]. Atlanta (GA): Centers for Disease Control and Prevention; 2011. Available: www.cdc.gov/obesity/childhood /prevalence.html. (accessed 2011 July 11).

15. American academy of paediatrics. National cholesterol education program: Report of the expert panel on blood cholesterol levels in children and adolescents. Pediatrics 1992;89:525-84

16. National High Blood Pressure Education Program Working Group on High Blood Pressure in Children and Adolescents. The fourth report on the diagnosis, evaluation, and treatment of high blood pressure in children and adolescents. Pediatrics 2004;114:555-76.

17. McCrindle BW, Manlhiot C, Millar K, et al. Population trends toward increasing cardiovascular risk factors in Canadian adolescents. J Pediatr 2010;157:837-43.

18. Khoury M, Manlhiot C, Dobbin S, et al. Role of waist measures in characterizing the lipid and blood pressure assessment of adolescents classified by body mass index. Arch Pediatr Adolesc Med 2012 Apr. 2 [Epub ahead of print].

19. Sun SS, Grave GD, Siervogel RM, et al. Systolic blood pressure in childhood predicts hypertension and metabolic syndrome later in life. Pediatrics 2007;119:237-46.

20. Gangwisch JE, Malaspina D, Babiss LA, et al. Short sleep duration as a risk factor for hypercholesterolemia: analyses of the national longitudinal study of adolescent health. Sleep 2010;33:956-61.

21. Kong AP, Wing YK, Choi KC, et al. Associations of sleep duration with obesity and serum lipid profile in children and adolescents. Sleep Med 2011;12:659-65.

22. Javaheri S, Storfer-Isser A, Rosen C, et al. Sleep quality and elevated blood pressure in adolescents. Circulation 2008;118:1034-40.

23. Spruyt K, Molfese DL, Gozal D. Sleep duration, sleep regularity, body weight, and metabolic homeostasis in school-aged children. Pediatrics 2011;127:e345-52.

24. Chaput JP, Lambert M, Gray-Donald K, et al. Short sleep duration is independently associated with overweight and obesity in Quebec children. Can J Public Health 2011;102:369-74.

25. Taheri S, Lin L, Austin D, et al. Short sleep duration is associated with reduced leptin, elevated ghrelin, and increased body mass index. PLoS Med 2004;1:e62.

26. Kudo T, Horikawa K, Shibata S. Circadian rhythms in the CNS and peripheral clock disorders: The circadian clock and hyperlipidemia. J Pharmacol Sci 2007;103:139-43

27. Gupta NK, Mueller WH, Chan W, et al. Is obesity associated with poor sleep quality in adolescents? Am J Hum Biol 2002;14:762-8.

28. Bénéfice E, Garnier D, Ndiaye G. Nutritional status, growth and sleep habits among senegalese adolescent girls. Eur J Clin Nutr 2004;58:292-301.

29. Going SB, Lohman TG, Cussler EC, et al. Percent body fat and chronic disease risk factors in U.S. Children and youth. Am J Prev Med 2011;41:S77-86.

30. Lamb MM, Ogden CL, Carroll MD, et al. Association of body fat percentage with lipid concentrations in children and adolescents: United states, 1999-2004. Am J Clin Nutr 2011;94:877-83.

31. Ledoux S, Choquet M, Manfredi R. Self-reported use of drugs for sleep or distress among french adolescents. J Adolesc Health 1994; 15:495-502.

32. Bradley TD, Floras JS. Obstructive sleep apnoea and its cardiovascular consequences. Lancet 2009;373:82-93.

33. Verhulst SL, Schrauwen N, Haentjens D, et al. Sleep-disordered breathing in overweight and obese children and adolescents: Prevalence, characteristics and the role of fat distribution. Arch Dis Child 2007;92:205-8.

34. McQueen MJ, Hawken S, Wang X, et al. Lipids, lipoproteins, and apolipoproteins as risk markers of myocardial infarction in 52 countries (the Interheart Study): A case-control study. Lancet 2008;372:224-33.

35. Steiner MJ, Skinner AC, Perrin EM. Fasting might not be necessary before lipid screening: A nationally representative crosssectional study. Pediatrics 2011;128:463-70.

36. Friedman HS, Martin LR, Tucker JS, et al. Stability of physical activity across the lifespan. J Health Psychol 2008;13:1092-104.

37. Juonala M, Juhola J, Magnussen CG, et al. Childhood environmental and genetic predictors of adulthood obesity: the Cardiovascular Risk in Young Finns Study. J Clin Endocrinol Metab 2011;96:E1542-9.

38. Freedman DS, Khan LK, Serdula MK, et al. The relation of childhood BMI to adult adiposity: the Bogalusa Heart Study. Pediatrics 2005;115:22-7.

Affiliations: From the Department of Respiratory Medicine (Narang) and Labatt Family Heart Centre (McCrindle, Manlhiot, Davies-Shaw, Chahal), University of Toronto, The Hospital for Sick Children, Toronto, Ont.; and Heart Niagara Inc. (Gibson, Stearne, Fisher, Dobbin), Niagara Falls, Ont.

Contributors: Cedric Manlhiot, Don Gibson, Nita Chahal and Stafford Dobbin contributed to the conception and design of the study. Don Gibson, Karen Stearne, Amanda Fisher and Stafford Dobbin were involved in the acquisition of data. Indra Narang, Cedric Manlhiot and Brian McCrindle were involved in the analysis and interpretation of the data. They, along with Jolie Davies-Shaw, drafted the manuscript. All of the authors were involved in the revision of the manuscript. and approved the final version submitted for publication.

Funding: This work was supported by the CIBC World Markets Children's Miracle Foundation Chair in Child Health Research and a Canadian Institute of Health Research team grant in childhood obesity. The study sponsors had no role in the design of the study, the collection, analysis or interpretation of data, the writing of the report or the decision to submit the article for publication. 